Научная статья

УДК 111

DOI 10.18101/2306-630X-2020-2-10-19

\title{
КАТЕГОРИЯ «БЫТИЕ» В БУДДИЙСКОЙ И ХРИСТИАНСКОЙ КУЛЬТУРАХ
}

\author{
(C) Тыхеев Владимир Валерьевич \\ аспирант, \\ Бурятский государственный университет имени Доржи Банзарова \\ Россия, 670000, г. Улан-Удэ, ул. Смолина 24a \\ vvtcaf@yandex.ru
}

\begin{abstract}
Аннотация. Статья посвящена межкультурной проблематике буддийской и христианской культур, рассматриваемой в контексте сравнительного анализа понимания категории «бытие» в этих двух культурах. В качестве основного фактора, определяющего особенности буддийской цивилизации, рассматривается наиболее влиятельная доктрина буддизма Махаяны о природе Будды в каждом живом существе (учение о Татхагатагарбхе) и об онтологической тождественности сансары и нирваны, а также подчеркивается значение буддийской доктрины об «анатман», постулирующей «динамичную» концепцию личности, представляющую собой непрерывно изменяющийся «поток сознания», не имеющий статичной природы и потому способный на любые изменения в способе своей социальной деятельности. С другой стороны, рассматривается близкая по социальным последствиям христианская концепция личности, основанная на рецепции аристотелистской онтологии, произошедшей в томизме, и на мистическом опыте некоторых католических святых об отсутствии самостоятельного существования человеческой личности. На основании такой схожести антропологических концепций буддийской и христианской доктрин показывается неслучайность существующего плодотворного межцивилизационного взаимодействия буддийской и христианской культур. Ключевые слова: буддизм; христианство; природа Будды; сансара; нирвана; томизм; аристотелизм; анатман; йогачара; ваджраяна.
\end{abstract}

\section{Для цитирования}

Tblхеев B. B. Категория «бытие» в буддийской и христианской культурах // Евразийство и мир. 2020. № 2. С. 10-19.

По одному из общепринятых словарных определений, «бытие - категория, фиксирующая основу существования (для мира в целом или для любой разновидности существующего); в структуре философского знания выступает предметом онтологии» ${ }^{1}$. Под это определение вполне подпадает, конечно, и социальное бытие, являющееся целостной взаимосвязью человеческих отношений и культурных форм, возникших в результате этих взаимоотношений; сущностной особенностью человеческих взаимоотношений (экономических, биологических, идеологических, психологических, духовных) является наличие общественного сознания, понимаемого как пространство объективного существования конкретной культуры и ее неотъемлемых функций (адаптивной, интегративной, коммуникативной, социализирующей, компенсаторной). Какая из этих функций является определяющим фактором,

\footnotetext{
${ }^{1}$ История философии // Энциклопедия / под ред. А. А. Грицанова. Мн.: Интерпрессервис, 2002. C. 139.
} 
Tыхеев B. B. Категория «бытие» в буддийской и христианской культурах

формирующим конкретное общественное сознание, существующее в конкретном обществе и конкретной культуре?

На этот вопрос существует несколько ответов, данных в истории развития социальной философии; в качестве примеров можно привести несколько концепций: мы знаем о марксистской точке зрения, рассматривающей все через призму определяющего фактора общественного производства — и эта теория, необходимо признать, с большой долей исторической достоверности описывает социально-экономические феномены, которые действительно влияют на общественное сознание отдельных народов, социальных классов, а также, естественно, на индивидуальное сознание их отдельных представителей (неизбежно являющееся в той или иной степени частью общественного сознания). Мы знаем также о точке зрения основателя социологии О. Конта, видящего развитие общественного сознания (которое, с его точки зрения, определяет политико-экономическое развитие) преимущественно как историю трансформации господствующих в обществе идей, от мифологических до научных, «позитивных»; и эта точка зрения также отражает действительные (и, по общепринятому в научной среде пониманию, прогрессивные) перемены в массовом сознании, заключающиеся в смещении приоритетов культуры в сторону более рационального понимания и действия людей в рамках меняющегося социума. Конечно же, вышеупомянутые концепции могут претендовать лишь на частичное, неполное познание социальной реальности; ведь любая теория создает лишь картину мира — мир в целом, в его всеобъемлющей полноте остается загадкой для ограниченных возможностей человека; мы можем лишь стремиться к более полному пониманию бытия.

В этой статье мы рассмотрим влияние религиозных традиций Востока и Запада на понимание бытия вообще и социального бытия в частности в менталитетах разных народов; на наш взгляд, способ истолкования человеком своего экзистенциального (конкретного, единичного, конечного, личностного, обладающего свободой, ищущего высший смысл своей жизни) бытия во многом определяет сами возможности общественного сознания (которое определяется деятельностью индивидуальных сознаний, а с другой стороны, формирует эти индивидуальные сознания) к пониманию тех или иных идей, того или иного опыта — для их актуализации в социальной реальности. В свою очередь, понимание «эпистемологических механизмов» (законов, по которым формируется вся понятийно-аксиологическая структура общественного сознания) такого рода рецепций может дать ключ к пониманию процессов взаимовлияния и взаимопроникновения и взаимообогащения разных национальных культур.

Конечно, возникает неизбежный вопрос о путях воздействий религиозных концепций на общественное сознание, а также вопрос о том, каким образом такое влияние религиозных традиций передается из поколения в поколение (проблематичность этого вопроса основана на том факте, что далеко не всегда представители следующего поколения бывают вообще знакомы с той или иной религиозной доктриной, не говоря уже о сознательной религиозной практике). В рамках данной статьи будет достаточным ответить на них следующим образом: средой передачи между поколениями духовного уровня понимания человеком себя и мира является конкретная национальная культура, всегда изначально растущая из религиозных представлений; ведь, как мы знаем, практически все известные национальные культуры имели мифологические, а затем и религиозные корни. 
Другими словами, мы будем исходить из такого понимания, что передача духовной культуры (понимаемой нами в данном случае как способ истолкования бытия и как способ человеческого существования в качестве духовного существа) от общества к каждому отдельному человеку осуществляется на том дорациональном уровне, когда в процессе воспитания в силу особенностей возраста ребенок не может ответить отказом на предлагаемое ему (родителями и иными взрослыми) смысловое и аксиологическое пространство, формируемое той или иной духовной традицией, передающейся из поколение в поколение через культуру. Такое понимание, на наш взгляд, вполне научно корректно в контексте фактически уже общепринятых в педагогике представлений о воспитании как о социализации (которая, в свою очередь, является приспособлением к определенной социальной среде - ее требованиям и ценностям).

I

Каково понимание бытия в буддизме? Если рассматривать в качестве буддийского учения традицию буддизма Махаяны как самую распространенную и самую развитую, то бытие там понимается в первую очередь как «природа Будды» (санскр. बुद्धधातु, Buddha-dhātu), которая присутствует в каждом живом существе и является «подлинной, неизменной и вечной природой всех существ» [1, с. 871-872] (в данной статье мы не будем рассматривать проблему понимания материального бытия в разных буддийских школах; нам важно буддийское понимание бытия человека и бытия человеческого общества; достаточным будет отметить, что материальное бытие рассматривается в буддизме Махаяны не иначе, чем рассматривается в нем бытие сознания; тоесть как непрерывно меняющийся поток дхарм; «реальное бытие может длиться только один момент, подобный одной миллиардной сверкания молнии» ${ }^{1}$ ).

Итак, буддийское понимание бытия имеет отчетливо монистический характер (понимаемый, конечно, в разных школах различным образом; мы исходим из основных школ буддизма Махаяны как наиболее представительных и «популярных»; одной из них является школа «Ваджраяна»); собственно под бытием понимается некая божественная (подлинная, неизменная и вечная) природа. По буддийскому учению (воспринятому буддизмом из брахманизма), причиной страданий и перевоплощений (потенциально бесконечных) является омраченность сознания различными привязанностями или «клешами» (главное из которых — привязанность к иллюзорному «я», формирующему эгоцентричное сознание как мир в котором существует человек).

Возникает вполне законный вопрос: так чем тогда принципиально отличается онтология и антропология брахманизма (классического индуизма) от онтологии и антропологии буддизма Махаяны? Ответ — в буддийской концепции (разделяемой в Махаяне) об отсутствии «я» в буддизме; «Ана́тман (санскр. अनात्मन्, anātman; пали: Анатта; букв. «не-я») - один из важнейших догматов буддизма, постулирующий отсутствие атмана - «я», самости индивида или его души. Вместо учения об атмане в буддизме присутствует учение о движущихся дхармах - неделимых «единицах психики», составляющих так называемую личность (пудгала — санскр.). Непрерывный поток дхарм называется «сантана» ${ }^{2}$.

${ }^{1}$ Вестник ЮУрГУ. 2011. № 30 (247) Серия «Социально-гуманитарные науки», выпуск 17. URL: https://cyberleninka.ru/article/v/problema-bytiya-v-buddiyskoy-filosofii (дата обращения: 4.10.2020).

${ }^{2}$ Анатма-вада. Новая философская энциклопедия // Электронная библиотека ИФ PAH. URL: https://iphlib.ru/library/collection/newphilenc/document/HASH017fd3f4fa8ab6bbab321f7f 
Tblхеев B. B. Категория «бытие» в буддийской и христианской культурах

Тогда как в индуизме понятие истинного «я» является фундаментальным во всей доктрине: атман (санскр. atman, «самость», «дух», «высшее я») — вечная, неизменная духовная сущность, абсолют, осознающий свое собственное существование. Термин используется для описания высшего «я» человека и всех живых существ ${ }^{1}$. Таким образом, в буддизме мы можем наблюдать в высшей степени «динамичную» концепцию личности, представляющую собой некий «поток сознания», который никогда не тождественен себе даже тому «я», которое было мгновение назад - этот поток непрерывно изменяется и может быть направлен в любую сторону, так как у человека - и только у человека, в отличие от других существ сансары, - существует возможность метафизического выбора (включая выбор в сторону высшего просветления).

В вышеизложенном контексте совершенно неслучайным выглядит такая известная концепция буддизма Ваджраяны (направление, возникшее в буддизме Махаяны в V в. н.э.), как тождество сансары и нирваны; «B "Тантре учителя" (Gyud-bla-ma), пишет Нацог-Рандол,- сказано: "элементы, имеющие предикаты с подлинным различением, обладают предикатами, не поддающимися различению посредством мгновенно очищенной пустой основы, и эти дхармы, не имеющие никого выше себя, не являются пустыми". Все являющееся реально - пусто, имманентно, ибо оно есть продукт иллюзорной (благодаря неведению) дифференциации. Но в то же время оно - трансцендентно, ибо, уничтожая неведение, индивид осуществляет интеграцию действительной ценности единого - дхармакаи, и, не смущенный неведением, видит в имманентном бытии трансцендентную дхармакаю, а во всех живых существах - будд. Дхармакая пуста лишь для сансарного индивида, для тех, кто "положил в основу истинность существования всего через вместерожденное неведение", для тех, чьи глаза привыкли различать лишь иллюзорную сансарную конкретность вещей и явлений. Для интегрировавшего в дхармакаю индивида шунья ее полна непередаваемых запредельных ценностей» (Сочинение, приписываемое Майтрейе («Уттаратантра») [2].

Здесь необходимо, забегая немного вперед, отметить, что данное ваджраянистское учение (являющееся, если можно так выразиться, одним из магистральных в современном мировом буддизме) из всех восточных доктрин (включая все направления индуизма и буддизма) наиболее близко к христианской онтологии (во всяком случае онтологии сотворенного существования, существующего через онтологическое - данное изначально вместе с фактом бытия - единство с Богом; «хотя Он и недалеко от каждого из нас: ибо мы Им живем и движемся и существуем» (Деян. 17:27,28)²; ведь фраза «дхармы, не имеющие никого выше себя, не являются пустыми» означает (в контексте всей процитированной цитаты, приписываемой Майтрейе-Натха, жившему около 270-350 гг.н.э. — одному из основателей школы «йогачара» буддизма Махаяны) то, что существующее существует для вечного бытия, уже являясь частью вечной природы Будды, — по крайней мере, все живое существующее призвано к вечному блаженному бытию, осуществляемому в человеке посредством духовной практики, ведущей к просветлению (которое, в свою

(дата обращения: 4.10.2020).

${ }^{1}$ Индийская философия. М.: Академический проект; Альма Матер, 2008. С. 28.

${ }^{2}$ Священное Писание Ветхого и Нового Заветов. Синодальный перевод. М.: Никея, 2016. C. 1362 . 
очередь, понимается в Ваджраяне как преодоление неведения высшей Реальности, в которой существует все сущее; соответственно, в христианской религии такое преодоление невежества называется верой, следуя которой индивид мистически через духовные практики - познает Божество во все более полном единстве с ним).

Пустотность феноменального бытия, о которой так определенно учит Махаяна («шуньята - это отсутствие собственной природы вещей и феноменов (дхарм) ввиду их относительности, обусловленности и взаимозависимости» [3, с. 943]), означает не только иллюзорность (ввиду непрерывного изменения всего видимого) всего постигаемого чувствами, но во-первых, аксиологическую не-ценность всего чувственного; в видимых вещах нет ничего, к чему можно было бы привязываться; во-вторых, отсутствие у них источника бытия в них самих (то есть они иллюзорны онтологически). Однако доктрина о тождественности сансары и нирваны открывает путь такому типу духовного пути, в конце которого практикующего эти принципы ждет просветление в той форме, когда он «не смущенный неведением, видит в имманентном бытии трансцендентную дхармакаю, а во всех живых существах — будд» («Дхармака́я, dharmakaya, «сущностное тело», «тело дхармы»,- высшее из трех тел Будды, абсолютное проявление духовной сущности, сущность мироздания, постижимая только посредством высшего просветления. В буддийской философии Мадхьямаке Дхармакая рассматривается в двух аспектах: как свабхавикакая («сущностное тело») - реальность с высшим онтологическим статусом, и как джнянадхармакая («тело гносиса/знания») - когнитивный аспект этой реальности; чистая недвойственная (санск. «адвая») мудрость, лишенная («пустая») какой-либо субъект-объектной дихотомии» $\left.{ }^{1}\right)$.

\section{II}

Если принять во внимание, что религия на протяжении долгого исторического времени являлась главным фактором, определяющим духовный облик конкретной культуры, то можно прийти к вполне последовательному выводу о том, что способ истолкования реальности, в которой живет человек, полностью определяется религиозными концепциями, свойственными данной духовной культуре. Ведь именно религией во многом (в разных культурах в различной степени) определялись этика и эстетика (мораль и искусство), философия и социальная и политическая практика, семейные и политические традиции и т. д.; все то, что сейчас принято включать в одно очень емкое понятие - «менталитет», под которым понимается образ мысли, эмоционально-смысловая структура мышления и сферы бессознательного (включая т. н. коллективное бессознательное), нравственно-духовные принципы, культура во всех ее аспектах.

Конечно, неизбежен вопрос: насколько в рамках современного секулярного общества (в которой религия нормативно не связана с остальными сферами и уровнями культуры) актуален такой подход к определяющим этот самый менталитет конкретного народа структурам мышления? На наш взгляд, культура как таковая по-прежнему находится под влиянием религиозного сознания; во всяком случае под его опосредованным влиянием; о каком культурном опосредовании может идти речь в данном случае? Во-первых, достаточно очевидным является факт существо1 Энциклопедия буддизма // Дхармакая. URL: http://vbuddisme.ru/wiki/Дхармакая (дата обращения: 05.10.2020). 
вания связи между человеческой моралью и религией; насильственная деструкция религии приводит либо к кризису моральных основ культуры (о неизбежности торжества нигилизма в эпоху «смерти Бога» предупреждали Достоевский и Ницше), либо к появлению квазирелигиозной идеологии, во многом в своих феноменах схожей с религиозностью как таковой (на примере КНДР это особенно очевидно). Во-вторых, герменевтическая и феноменологическая структура человеческого мышления (открытая в XX в. герменевтическим и феноменологическим, а также структуралистским и постструктуралистским философскими направлениями) свидетельствует о некой пред-заданности («способа понимания» и «способа существования»), унаследованной от религиозной традиции метафизикой (онтологией); выявленная Э. Гуссерлем интенциональность человеческого сознания включает в себя не только направленность на предмет, но и некое вкладывание смысла в этот предмет - причем данное вкладывание смысла имеет характер не только в контексте сознательной «феноменологической редукции» (понимаемой как путь к подлинному смыслу, заложенному в смысловых структурах культуры), но и бессознательного предрассудка, о котором свидетельствует герменевтика Г. Гадамера; смысловое пространство культуры в этом контексте есть не что иное как духовная природа человека как такового, от которой он не может быть свободным иначе (быть «вне» eе, другими словами), как редукцией к животному способу существования.

С такой точки зрения даже самая, казалось бы, секулярная культура несет в себе характерные черты той религиозной традиции, которая определила ее смысловое поле, ее «систему координат» - и вместе с ней определила природу человеческой личности как таковую. Таким образом, человек как таковой (с данной точки зрения) есть не что иное как та или иная духовная культура, существующая, если можно так выразиться, на «экзистенциальном биологическом носителе»; вопрос лишь о той степени актуализации заложенных в культуре духовных смыслов, которой достиг тот или иной человек (независимо от своего социального статуса).

Данная степень актуализации - если мы будем исходить из наличия свободы воли - относится к сфере моральной свободы; этику, аксиологию, эпистемологию и онтологию в рамках культуры (и в рамках конкретной личности, «воплощающей» конкретную культуру) невозможно разделить, на наш взгляд; конкретная национальная культура в этом контексте является органичным синтезом всех вышеперечисленных сфер духовной культуры, и в этом смысле становится вполне достоверным тезис об определяющем влиянии религиозной традиции на существующий «менталитет» (понимаемый как «образ мысли»; образ, сформированный духовной традицией). Ведь общественная солидарность (без которой невозможны стабильное общество и живая культура) подразумевает определенную смысловую и культурную матрицу, через которую она осуществляется, в которой смыслы, ценности, запреты и императивы объединены в единое целое, формирующее личность в процессе социализации.

Каковы черты, например, буддийской махаянской культуры? Человек рассматривается в ней как свободный и в то же время кармически обусловленный омраченностью сознания, непрерывно самоопределяющийся и борющийся с собой и с миром сансары за свою духовную свободу, непрерывно избирающий свой путь и способ истолкования мира (который - способ истолкования в соответствии с выбранной доктриной и избранным путем - собственно и «создает» тот реальный мир, име- 
нуемый сансарой, но в буддизме вадржаяны являющийся нирваной для каждого просветленного, видящего божественную природу в себе и в каждом человеке).

Трудно не обратить внимание на то, что данная культурная парадигма чрезвычайно напоминает эпистему христианской культуры («эпистема есть обусловленное исторически культурно-когнитивное априори, совокупность правил и отношений в конкретных месте и времени, формирующих условия существования исторических форм культуры и знания» [5, с. 636]), какой мы ее знаем после Возрождения; человек эпохи Возрождения (и тем более после нее) под влиянием общественноэкономических перемен, связанных с ростом городов (и их независимостью от центральной власти и от диктата церкви), осознает свою творческую свободу и безграничность мира (как мы знаем, то была эпоха и великих географических открытий), при этом оставаясь в рамках христианской доктрины (включающей в себя учение о глубокой поврежденности человеческой природы прирожденной греховностью), которая тем не менее подверглась достаточно радикальному обновлению через рецепцию аристотелизма в таком новом теологическом направлении католичества, как томизм, который уже в XIV в. был признан истинным учением католической церковью - наряду с другими, уже существовавшими, основанными на прежней неоплатонической парадигме.

Томистская рецепция аристотелизма положила начало радикально новому пониманию и эпистемологических возможностей человека; Фома Аквинат учил о сугубо эмпирическом характере всего доступного знания (за исключением высших интуитивных мистических озарений); определенное понимание иллюзорности представлений о мире имплицитно уже присутствовало в этом аристотелистском эмпиризме (как мы помним, эмпиризм вполне логично привел к учениям Беркли и Юма, поразительно схожим с индуистской и буддийской философиями) — таким образом, менталитет христианского Запада и в этом (эпистемологическом) отношении стал близок к мироощущению буддийского Востока.

И в этой схожести эпистем христианской и буддийской культур, на наш взгляд, кроется разгадка таких феноменов, как быстрая и во многих аспектах органичная (как бы совершенно естественная, приведшая к очевидному прогрессу 一 во всяком случае экономическому и социальному) культурная и экономическая вестернизация многих преимущественно буддийских народов (населяющих такие страны, как Тайвань, Сингапур, Южная Корея; Китай и Япония, как известно, также в большой степени подверглись влиянию буддизма; «вестернизация» Японии произошла во многом под влиянием американских оккупационных властей, но тем не менее также в большой степени органично и бесконфликтно) и сильнейший интерес в религиям Востока (и особенно - к школам буддизма Махаяны) который мы наблюдаем на Западе [5, с. 121].

С одной стороны, свойственное буддийской традиции интуитивное понимание человека как свободного, не привязанного ни к чему, кроме цепей своих привязанностей (омрачений сознания, основанных на невежестве - на неведении высшей божественной реальности), открывает широкий путь к принятию западных либеральных принципов (основанных, в свою очередь, на христианской религии, видящей человека высшим существом тварного бытия, призванного к свободе и творчеству); с другой стороны, именно христианская традиция заставляет мно- 
гих ее представителей стремиться к обогащению своей европейской мистической традиции духовными сокровищами Востока.

Вот один пример высказывания католического священника с межрелигиозной конференции (под религиями имеется в виду христианство и буддизм; Томас Мертон был католический монах, в высшей степени интересовавшийся буддизмом): «о. Томас Китинг OCSO "Гефсиманские встречи II" (апрель 2002 г., межрелигиозная конференция в аббатстве Томаса Мертона, США): Мы являемся одновременно и телом, и душой - мы воплощены. Одной из задач нашего духовного пути является обретение свободы от самоотождествления с собственными представлениями о себе. Нам необходимо перестать редуцировать себя до мимолетных телесных или психических ощущений, до собственной социальной роли. Как говорил Иисус пока ты не отречешься себя, не можешь быть Моим учеником (Мф 16, 24; Мк 8,34; Лк 9, 23)» ${ }^{1}[6]$. В качестве другого примера схожести буддийского и христианского подходов к природе человеческого сознания можно привести каноническое (одобренное Церковью) житие великой католической святой Екатерины Сиенской, где есть очень характерные в контексте этой статьи слова: «Путеводными для всей духовной жизни св. Екатерины стали слова, сказанные ей Христом в одном из видений: «Екатерина, Я есть Тот, Кто Есть; ты есть та, кого нет»².

Другими словами, речь идет о схожести буддийского и христианского менталитетов («образов мысли») в контексте общих принципов понимания онтологической природы личного и общественного сознания; этими общими принципами является осознание сугубой иллюзорности (ошибочности в суждениях и уверенности в неизменности «я»), динамичности, изменчивости индивидуального «я» (которое в рамках рассматриваемых парадигм Запада и Востока является сугубо иллюзорным; западный постструктурализм пришел к выводам, аналогичным тем, которые приняты на буддистском востоке); очевидна схожесть также буддистского понимания присутствия в человеке «природы Будды» с католическим учением о причастности каждого человека к божественной природе самим фактом своего существования (Фома Аквинат: «Бог есть существование всех вещей; не по сущности, но как Причина» [7, с. 41]. Именно эта схожесть, на наш взгляд, определяет такое качество современных буддийской и христианской культур, как способность к быстрым культурным и социально-экономическим переменам.

\section{III}

В этом контексте вполне корректным было бы рассмотреть и аналогичность «генеалогии» современной христианской и актуальной (существующей сейчас) буддийской культурных парадигм; в первом случае мы можем увидеть предшествующую средневековую неоплатоническую, во втором - индуистскую (брахманистскую) парадигмы. Христианское средневековье исходило из статичности и неизменности сотворенного бытия (являющегося не более чем копией, актуализацией вечных неизменных идей в разуме Бога; такое понимание мира не подразумевало возможность его развития), а брахманизм постулировал вечную божественную основу личного

${ }^{1}$ Священное Писание Ветхого и Нового Заветов. Синодальный перевод. М.: Никея, 2016. C. $1219-1398$.

${ }^{2}$ Святая Екатерина Сиенская. Память 29 апреля. URL:http://sib-catholic.ru/29-aprelyasvyataya-ekaterina-sienskaya-pamyat (дата обращения: 05.10.2020). 
индивидуального сознания (атмана) и бессмысленный круговорот перевоплощений, не создающий ничего нового и тем более лучшего; эти парадигмы оставляли лишь внутренний мир человека (как поле его моральной и мистической практики) для актуализации активного творческого потенциала человеческой природы.

Здесь возникает неизбежный вопрос о научной и этической корректности культурологического «европоцентризма» (в известной мере ответственного, например, за появление нацистской идеологии в различных ее формах); необходимо отметить, что предлагаемый нами подход к рассмотрению западной и восточной религиознокультурных эпистем (условно западно-христианской и дальневосточно-буддийской) как раз таки указывает на очевидную схожесть рассматриваемых культур уже на уровне глубины самопознания человеческого духа, осознавшего свой безграничный культуро-творческий потенциал (заключенный в незаданности «извне» ничем, кроме как высшей Реальностью, дающей бесконечные возможности).

Тот факт, что именно Европа стала исторически (хронологически - ранее других регионов) первенствовать в феноменах общественно-экономического прогресса, во многом обусловлен достаточно случайным историческим фактором - экспансией ислама. Исламская цивилизация была в эпоху крестовых походов более высокоразвитой, чем европейская; достаточно вспомнить, что знакомство европейских интеллектуалов с концепцией Аристотеля в версии аверроизма началось в испанской Мавритании, где учились в XI-XII вв. в университетах Толедо и Кордобы тысячи европейских студентов; именно угроза для католичества со стороны чрезвычайно распространившегося аверроизма подвигла Фому Аквината на создание католической аристотелистской онтологии [7, с. 47].

Подобно тому, как буддизм провозгласил полный отказ от опоры на «я» (которая — опора на «я» — была в брахманизме) с одновременным осознанием «природы Будды» как единственного реально существующего бытия, рецепция аристотелизма (с его динамической концепцией бытия и пониманием растительной, животной или человеческой души как активной формы, актуализирующей, оживляющей тело; «мир идей» оказался, по Аристотелю, внутри человека - в качестве активного творческого начала) в католическом томизме открыла путь иному (на наш взгляд, более аутентичному христианским смыслам и много более, чем неоплатонизм, соответствующему историческим вызовам, наступившим после конца Средневековья) пониманию христианской традиции; пониманию, открытому свободе самоопределения и творчества.

Такая во многом подобная трансформация общественного сознания (произошедшая через смену религиозной эпистемы) на Дальнем Востоке произошла на тысячу лет раньше, чем на Западе (речь о распространении буддизма на Дальнем Востоке); по иронии судьбы в полной мере социальные плоды такой модернизации были получены на Западе и пришли на Восток с Запада. По всей видимости, причинами такой «асинхронности» является сугубо катастрофический характер европейской истории, свойственный эпохам, наступившим вслед за распадом восьмисотлетней европейской средневековой культурной парадигмы (которая по статичности - если не сказать косности - могла дать фору любой дальневосточной цивилизации). «Постиндустриальная» модернизация культуры на Дальнем Востоке произошла поразительно органично и неконфликтно, с использованием европейского опыта, но на глубочайших основах собственной культуры. 
Лuтература

1. Канаева Н. А. Татхагата-гарбха // Философия буддизма: энциклопедия / отв. ред. М. Т. Степанянц. М.: Вост. лит., ИФ РАН, 2011. 1045 с.

2. Железнов А. И., Пупышев В.Н. Тексты канона Русского Буддизма // Учение важраяны о тождестве сансары и нирваны. URL: http://dandaron.ru/rus/theory/sansara_and_nirvana. html\#5 (дата обращения: 5.10.2020)

3. Канаева Н. А. Татхагата-гарбха // Философия буддизма: энциклопедия / отв. ред. М. Т. Степанянц. М.: Вост. лит., ИФ РАН, 2011. 1045 с.

4. Визгин В.П. Современная западная философия. Энциклопедический словарь / под ред. О. Хёффе, В. С. Малахова, В. П. Филатова при участии Т. А. Дмитриева. Ин-т философии РАН. М.: Культурная революция, 2009. 793 с.

5. Аякова Ж.А. Об «Американизации» буддизма // Вестник Бурятского государственного университета. 2014. Т. 14, вып. 1. С. 119-123.

6. Китинг Т. Гефсиманские встречи II // Раннехристианские святые рекомендуют медитировать. URL: https://catholic-russia.livejournal.com/94691.html (дата обращения: 5.10.2020).

7. Свежавски С. Фома Аквинский, прочитанный заново. М.: МЦИФИ, 2000. 212 с.

\section{CATEGORY OF BEING IN BUDDHIST AND CHRISTIAN CULTURES}

\section{Vladimir V. Tykheev}

Research Assistant of Philosophy Department

Dorzhi Banzarov Buryat State University

24a Smolina St., Ulan-Ude 670000, Russia

vvtcaf@yandex.ru

Abstract. The article considers the intercultural issues of Buddhist and Christian cultures in the context of a comparative analysis of understanding the category of "being" in these two cultures. We regard the most influential doctrine of Mahayana Buddhism about the nature of Buddha in every living being (the Tathāgatagarbha doctrine) and the ontological identity of samsāra and nirvana as the main factors determining the features of Buddhist civilization, and emthasize the importance of the Buddha's doctrine of anatta postulating the "dynamic" concept of personality, which is a continuously changing stream of consciousness "that does not have a static nature and therefore is capable of any changes in the way of its social activity. On the other hand, a Christian concept of personality is close in social consequences, and based on the adoption of Aristotelian ontology, which took place in Thomism and the mystical experience of some Catholic saints, who believed in the absence of an independent existence of the human person. This similarity of anthropological concepts of Buddhist and Christian doctrines shows that the intercivilizational interaction of Buddhist and Christian cultures it is not accidental.

Keywords: Buddhism; Christianity; Buddha-nature; saṃsāra; nirvana; Thomism; Aristotelianism; anatta; Yogachara; Vajrayāna.

Статья поступила в редакцию 30.09.2020; одобрена после рецензирования 30.10.2020; принята к публикации 11.12.2020. 